\title{
Os estudos do lazer e da comunicação: aproximações entre o "técnico" e o "estético" na rede ${ }^{1}$
}

\author{
The leisure studies and communication: approaches between the \\ "technical" and the "aesthetic" on the web
}

\author{
Juliana de Alencar Viana
}

Professora da Prefeitura Municipal de Congonhas (MG), Mestre pelo Programa de Mestrado (interdisciplinar) em Lazer pela Universidade Federal de Minas Gerais (UFMG), pesquisadora do Oricolé - Laboratório de pesquisa sobre formação e atuação profissional em lazer (UFMG), Belo Horizonte, MG - Brasil, e-mail: gaiajones@gmail.com

\begin{abstract}
Resumo
Este trabalho busca reconhecer a vida social que pulsa a partir do fenômeno da cibercultura e dirige o olhar às diversas manifestações do lazer na rede em busca da compreensão de seus sentidos e significados. Parece claro que o computador tornou-se um instrumento privilegiado de trabalho, consumo e, também, fonte de novos prazeres e divertimentos, o que sugere a necessidade de novos mediadores culturais no campo do lazer, criando novos parâmetros de intervenção para o profissional deste campo. Como desdobramento de alguns estudos, evidenciamos que a estetização e a politização das tecnologias podem se constituir como um aspecto da vivência do lazer na rede, por meio dos usos, apropriações e desvios. Aponto, portanto, o ciberespaço como um novo espaço de intervenção educativa, em um contexto social cada vez mais marcado pelo imperativo do acesso e conexão à internet.
\end{abstract}

Palavras-chave: Lazer. internet. Cibercultura.

\footnotetext{
1 Esse artigo é um desdobramento da minha dissertação de mestrado intitulada "Lazer e Tecnologias da Informação e Comunicação (TICs): desafios para pensar a Animação Cultural na rede - um estudo da comunidade EstudioLivre.org., defendida em março de 2010, sob a orientação do Prof. Dr. Victor Melo, no Programa de Mestrado em Lazer, da Escola de Educação Física, Fisioterapia e Terapia Ocupacional da Universidade Federal de Minas Gerais.
} 


\begin{abstract}
This paper aims to recognize the social life pulsing from the cyberculture phenomenon and directs the eye to the various manifestations of leisure on the web, in search for understanding of its senses and meanings. It seems clear that the computer has ultimately become an instrument for work, consumption, and also a source of new pleasures and amusement, which suggests the need for new cultural mediators in the leisure, creating new intervention parameters for the professionalin this field. We have found, as an outcome of some studies, that aestheticization and politicization of technologies may be constituted as an aspect of the experience of leisure on the web through its uses, appropriations and deviations. So, I point the cyberspace as a new area for educational intervention in a social context increasingly marked by the imperative of access and connection to the internet.
\end{abstract}

Keywords: Leisure. internet. Cyberculture.

\section{Introdução}

Se a tecnocultura moderna foi o paraíso de Apolo, a cibercultura pós-moderna parece ser o teatro de Dioniso (LEMOS, 2004, p. 259).

Para situar o lazer da internet e o atual contexto cultural, a epígrafe nos parece provocante e convidativa. Como pensar o estético a partir de um fenômeno técnico num tempo social em que os limites entre trabalho e lazer estão cada vez mais tênues? Apesar de suas características fundantes serem bastante distintas, para muitos teóricos da cibercultura, é preciso reconhecer a vida social que pulsa a partir deste fenômeno baseado no desenvolvimento da técnica, que teve em seu processo histórico a participação de diferentes atores sociais, entre eles militares, acadêmicos e ativistas. Dirigir o olhar às manifestações do lazer na internet significa analisar e investigar os impactos da tecnologia da informação e comunicação no tecido social e, para isso, compreender os sentidos e significados de práticas que jogam com uma apropriação dionisíaca a partir do desenvolvimento da tecnocultura moderna.

A cibercultura é resultado da apropriação tecnológica - fruto da sinergia da Big Science, dos militares e do underground e, hoje, associa a assepsia científica e tecnológica ao caos urbano e ao lado dionisíaco da socialidade contemporânea (LEMOS, 2004). Com surgimento nos anos 1950 , se populariza nos anos 1970, se estabelece em 1980 e, finalmente, se populariza nos anos 1990, com o aprimoramento das interfaces de navegação. Interessante notar que, de acordo com Levy (1999), em geral, a taxa de crescimento das conexões com o ciberespaço demonstra uma velocidade de apropriação social superior a todos os sistemas anteriores de comunicação.

Dessa forma, pensar a cultura contemporânea implica na compreensão das transformações da técnica, sabendo que estas alteram fortemente as relações sociais. Quando pensamos nas revoluções históricas (vapor, eletricidade e informação) e na atualização das tecnologias, imediatamente atentamos para as modificações no campo do trabalho, da cultura, da economia dentre tantas outras. Com o lazer não é diferente.

Sabendo que a produção ou conquista do tempo livre esteve associada historicamente com as revoluções técnicas e tecnológicas, encontramos uma infinidade de práticas e vivências de lazer - considerado um fenômeno tipicamente moderno - desde a Revolução Industrial, culminando atualmente na terceira grande revolução causada pelas tecnologias digitais. A produção de uma sociedade em rede não só produziu a extinção de alguns postos de trabalho como alavancou novos, e, principalmente, tornou o computador um instrumento privilegiado de trabalho, além de veículo para o consumo e fonte de novos prazeres e divertimentos, tornando a relação entre lazer e trabalho difusa e ambígua.

A popularização da internet tornou-se um ícone da sociedade da informação servindo de 
interface para atividades profissionais e também de vivências do lazer, o que demonstra a sua ambiguidade e imprecisão de seus múltiplos aspectos: entretenimento, consumo, desenvolvimento social e pessoal. No que se refere à compreensão do tempo, com implicações para o trabalho e o lazer, antes a regulação do tempo era dado pela máquina e os modos de produção - hora de trabalho - hoje é acrescido por aquilo que se produz de informação no tempo - kilobyte por segundo ou kbps - e falamos em velocidade de conexão, redes, sistema de informação, fluxo informacional, transferência e bancos de dados. Nesse sentido, a interatividade e conexão se tornaram um imperativo da contemporaneidade e, o conhecimento, a força propulsora da Economia, (KUMAR, 1997) constituindo-se como a nova moeda de troca e objeto de disputa de poder.

Buscando compreender tal fenômeno no atual contexto sociohistórico, parece que a sociedade da informação carrega traços de saturação dos ideais de modernidade (razão, progresso, futuro) que aliada às novas possibilidades da microeletrônica parece proporcionar o surgimento de novas formas de sociabilidade:

a modernidade se caracterizou por uma conjunção de fatores: por uma dominação técnica do social, por um individualismo exacerbado, por um constrangimento social exercido por uma moral burguesa e uma ética da acumulação, por uma abordagem racionalista do mundo. A modernidade, ao mesmo tempo, lançou e esgotou o sonho tecnológico. O que chamamos de novas tecnologias situa-se num novo contexto sociocultural, numa nova ambiência social. A tecnologia que foi o principal instrumento de separação, de alienação, do desencanto do mundo (Weber) e do individualismo positivista, vê-se investida pelas potências refutadas pelo racionalismo moderno (LEMOS, 2004, p. 16).

A cibercultura joga com a tecnocultura e oferece indícios de permanência e de ruptura, pois aproxima a técnica do prazer estético e comunitário e, por isso, torna-se vetor de novas experiências. Em todos os lugares, a tecnologia mistura utilidade e objetividade com despesa improdutiva (BATAILLE, 1975), racionalidade e imaginário, funcionalidade e estética. Ao lado dos processos técnicos encontramos a afirmação dos processos irracionais (desejos, afetos, excessos) que se encontram potencializados pelos novos recursos tecnológicos (LEMOS, 2004), ao mesmo tempo em que o lazer firma-se como um valor na contemporaneidade.

Dessa maneira, o teórico Dumazedier (1994) traz como fio condutor ao longo de sua análise a hipótese de que o tempo livre criado na sociedade é uma fonte de revisão ética e estética das relações dos indivíduos consigo mesmos, com os outros e com o ambiente. Para ele, este lazer é um tempo de expressão de si mesmo, individualmente ou em grupo, sendo espaço de emergência de práticas sociais cada vez mais variadas, mais sedutoras e ambíguas. Dessa forma, os modos de expressão disponíveis no ciberespaço já são bastante variados e serão ainda mais no futuro. Desde simples hipertextos ou filmes em vídeo digital, passando pelos modelos para simulação gráfica interativa e pelas performances em mundos virtuais, entre outros, tais práticas se constituem como novas formas de linguagem (LEVY, 1999).

Em função da inserção de novas tecnologias e da redefinição dos tempos sociais, o lazer, portanto, surge como uma necessidade que tem se reafirmado na contemporaneidade. As redes sociais online e as comunidades virtuais abrigam uma diversidade de atores em busca de novos sentidos e significados, o que inclui uma infinidade de práticas ciberativistas. Tais manifestações parecem se situar no campo do lazer, considerando uma perspectiva de fruição, que oferece linhas de fuga ao ordinário, às obrigações, ao caráter produtivo e de interesses meramente financeiros.

Tais comunidades emocionais são cada vez mais comuns e se articulam em torno de questões ora provisórias, ora permanentes. Dentro do movimento de fusão progressiva da vida com a tecnologia, torna-se também muito evidente a hibridização da techné com a aisthesis (SODRÉ, 2006) que escapam do controle do Estado.

$\mathrm{Na}$ mesma linha, Dumazedier (1994) também reforça aquilo que nasce fora do tempo social que as instituições controlam. Logo, é preciso reconhecer a pluralidade de vivências da internet no tempo livre e ter discernimento da heterogeneidade de suas práticas. Por isso, parece interessante criar 
aproximações entre a teoria e a empiria, a fim de criar novos parâmetros de intervenção para o profissional do lazer, em novas frentes de atuação, como o ciberespaço, pois o excesso informacional também gera a necessidade de novos mediadores culturais:

é assim que no fundo da multiplicidade das atividades de lazere de suas funções se encontra uma valorização temporária de uma individualidade mais liberada. Ela acumula todas suas forças ipsativas numa autonomia intersticial onde viver por viver é a finalidade primeira através de um caminhar sem rumo que não é forçosamente anomia. Uma ética da expressão mais livre de si substitui aqui uma ética de integração repressiva. [...] Todas estas metamorfoses da individualidade valorizada pela extensão do tempo livre e pela preponderância das atividades de lazer foram às vezes reduzidas a fenômenos "psicológicos", ignorando que o indivíduo e suas funções são em primeiro lugar produtos da história [...] (DUMAZEDIER, 1994, p. 51).

O lazer, hoje, significa uma afirmação de si mesmo em face do trabalho e das outras instituições de base da cidade. Este tempo privilegiado é uma conquista social, abrindo novas possibilidades às diversas formas possíveis de expressão individual, independente da participação institucional que, por vezes, ainda persiste em um modelo utilitário bastante explorado. Para Dumazedier (1994), é na valorização desta identificação social mais espontânea, mais renovada e passional a grupos de "iguais" que reside, provavelmente, a força manifesta ou oculta do lazer na vida cotidiana.

No atual contexto, algumas das formas de socialidade estão situadas nas festas tecno, raves, na navegação frívola no ciberespaço, na produção de vírus de computador, na invasão de sistemas, na troca de futilidades e, também, na constituição de comunidades. Todas estas formas são caracterizadas muitas vezes pelo presenteísmo, tribalismo, erotismo, violência, hedonismo, marcas da contemporaneidade para muitos antropólogos.

O campo de estudos do lazer, caracterizado como interdisciplinar, buscar reconhecer e compreender tais práticas e manifestações, frequentemente identificados pelo caráter frívolo, de despesa e de excesso improdutivo na rede (BATAILLE, 1975), constituindo novos objetos de investigação, o que sugere a utilização de novas lentes de análise, dada a complexidade da contemporaneidade e a necessidade de acionar diferentes aportes teóricos para a sua compreensão.

Dentro desse universo, encontramos sujeitos interessados na politização - acesso e uso justo e ético das tecnologias da informação e comunicação - e estetização-a produção de sentido na relação-destas tecnologias observadas na vida cotidiana e que são próprias de uma cultura urbana:

o exercício de politização enquanto prática cultural se pretendia autônomo e com uma tendência para a autogestão, amparada pelo conceito popularizado de "cultura digital". Coletivos com Metá:fora e Estúdio Livre foram laboratórios de experimentos partilhados da nova "cultura política”, intimamente ligada ao Software Livre; coletivos atravessados, contudo, por polêmicas e por tentativas de buscar o consenso em suas tomadas de decisão (MURILLO, 2009, p. 131).

Esse cenário abriga um investimento social enorme em novas formas de sociabilidade e expressão por meio de inúmeras redes sociais - Orkut, Twitter, Lastfm, Blip.fm, Vimeo, Youtube, Facebook, Flickr, Tumblr, Wordpress e outras - comunidades virtuais, novos modos de subversão da ordem econômica (compartilhamento de arquivos) e de movimentos sociais (ciberativismo) baseados em comunidades de prática cujo engajamento se dá por meio da partilha do sensível. As formas culturais emergentes, caracterizadas pelo cruzamento da informática com as telecomunicações, reforçam enormemente uma aproximação com a estética. Para Sodré (2006), o afeto, como potencial interativo e operatório, é tanto marco conceitual das estratégias de marketing como das expressões de sensibilidade das massas.

A questão da desterritorialidade na cibercultura também exige uma redefinição da noção de comunidade. Sodré (2006) adota o termo "comunidades emocionais", dada a convergência da sociabilidade com as novas tecnologias no compartilhamento de valores, objetivos e um sentimento de pertencimento para sua constituição. Uma comunidade virtual é construída sobre as 
afinidades de interesses, de conhecimentos sobre projetos mútuos, em um processo de cooperação ou de troca, independente das proximidades geográficas e das filiações institucionais (LEVY, 1999).

É inegável que a comunicação digital multiplicou os espaços e circuitos de acesso ao sabere à formação cultural, daí, a importância de incorporar e explorar tal temática no campo de estudos do lazer, o que reforça, inclusive, a necessidade de novos mediadores (MELO, 2006).

\section{Reconhecendo iniciativas: comunidades virtuais e redes sociais online}

Por meio de uma comunicação mediada por computador, diversas práticas e vivências operam nesse tempo social, cuja linha tênue dificulta uma oposição permanente entre trabalho e lazer. Ainda, o surgimento das novas tecnologias e toda a mudança cotidiana que ela traz exige a redefinição dos paradigmas para que deem conta de compreender as dinâmicas sócioculturais da atualidade. Para Sodré (2006), é particularmente visível a urgência de uma outra posição interpretativa para o campo da comunicação, capaz de liberar o agir comunicacional das concepções que o limitam ao grau de interação entre forças puramente mecânicas e de abarcar a diversidade da natureza das trocas.

no campo da comunicação, porém, a mera reiteração do surgimento de uma "outra cultura" vertebrada pelas tecnologias da informação não se faz acompanhar de uma outra atitude epistemológica ou interpretativa - mais compreensiva, menos intelectual-racionalista, capaz de apreender os fenômenos fora da medida universal-para a análise que se pretende chamar de "comunicacional" (SODRÉ, 2006, p. 14).

Nesse novo cenário comunicacional e relacional, cabe explorar as proposições de Dumazedier (1994), ao enfatizar a valorização do caráter divertido, ${ }^{2}$ termo que, por vezes, sofre de uma compreensão restrita, sendo pouco acionado. Assim, o autor reitera a vivência de um tempo que não é só aquele do dinheiro, o que encontra correspondência com diversas práticas de lazer na internet. Para escutar a vida social que fala por meio dos artefatos tecnológicos contemporâneos (LEMOS, 2004), parece necessário reconhecer a ação dos sujeitos que irão compor o mosaico de forças entre a tecnologia e a vida social.

Dessa forma, parece oportuno dialogar com algumas práticas das comunidades de software livre que operam com a constituição de uma espécie de dádiva moderna (AGUIAR, 2007). Para o autor, a internet comporta um tipo de engajamento não contratual e voluntário que pode ser identificado em diversas comunidades virtuais, cuja manifestação sugere uma nova expressão da dádiva moderna, uma dádiva mediada por computador, baseada na tríade de dar, receber e retribuir. Também nessa direção, Levy (1999) indica que a moral implícita da comunidade virtual é em geral a da reciprocidade, corroborando com as proposições de Aguiar (2007).

Aguiar (2007), atualiza o conceito de dádiva, proposto por Marcel Mauss (1988), ao investigar esse fenômeno típico da cibercultura. Para ele, as relações implicadas na constituição de comunidades virtuais não estão classificadas, exclusivamente, em termos de compra e venda, pois "as coisas têm ainda um valor de sentimento para além do mundo venal" (MAUSS, 1988 apud AGUIAR, 2007, p. 63). Completa ainda afirmando que, como demonstrou Godbout (2002), no seu artigo sobre Homo donator versus Homo oeconomicus, "torna-se muito difícil para um indivíduo moderno conseguir pensar num sistema de produção e circulação de bens e serviços sem se referir às interpretações e limitações inerentes ao paradigma neoliberal dominante" (AGUIAR, 2007, p. 75).

Parece importante salientar que o conceito de dádiva utilizado por Aguiar (2007) opera com um jogo constante entre obrigatoriedade e liberdade. O livre e o gratuito se misturam com o obrigatório e o interessado que, entre os hackers, parece significar a busca por reconhecimento e reputação. Cabe, portanto, esclarecer que a dádiva, encontra interfaces com as manifestações do lazer

\footnotetext{
2 MARZANO, A.; MELO, V. A. (Org.). Vida divertida: histórias do lazer no Rio de Janeiro (1830-1930). Rio de Janeiro: Apicuri, 2010.
} 
contemporâneo, dado seu caráter difuso e ambíguo, que é assim definido por Murillo (2009, p. 87):

[...] como toda prestação de bem ou serviço efetuado, sem garantia de retorno, que visa criar, alimentar ou recriar o elo social entre pessoas e assume características ambíguas como obrigação, espontaneidade, interesse (por) e prazer (interesse em). [...] Para Caillé a noção de interesse deve ser desmembrada em "interesse por" e "interesse em", representando respectivamente o interesse instrumental e exterior em relação a uma atividade social e o interesse pela realização de atividades por prazer nas quais há o sentimento de estar/ser incluído.

Em seu trabalho sobre a comunidade Gnome (AGUIAR, 2007), o autor recupera o ciberativismo de hackers que se esforçam globalmente para a criação de um ambiente de trabalho completo, gratuito e composto inteiramente por software livre. Nesta direção, o trabalho de Aguiar (2007) encontra pontos de intersecção com o de Murillo (2009), ao investigar comunidades virtuais que adotam os mesmos princípios e práticas, nas quais a questão da ambiguidade da dádiva parece se revelar, característica expressa, portanto, no campo do lazer na rede:

quando questionados sobre as razões pelas quais trabalham como voluntários, os desenvolvedores (backers) respondem de forma recorrente que a diversão, a busca e o compartilhamento do conhecimento, a tessitura de novos laços e a maior margem de atuação para tomar decisões são fundamentais. Seria algo como a priorização do interesse em tecnologias livres a anteceder ou a se misturar com o interesse por retornos financeiros: diversão porque ao trabalhar num pacote ou tradução você acaba aprendendo muito, superando o conhecimento que existia anteriormente - a sensação de entregar um trabalho - sensação de realização, superação, reconhecimento (Fike, entrevista dia 13/05/2007) (MURILLO, 2009, p. 90).

Seus colaboradores (comunidade GNOME) são de diversas nacionalidades e se manifestam contrariamente a qualquer forma de privatização do conhecimento e de propriedade intelectual, valorizando o uso de licenças flexíveis na circulação de seu trabalho imaterial, o que acaba por reforçar a questão da autoria coletiva na contemporaneidade situada nas formas GPL, ${ }^{3}$ para softwares, e de outro lado, o Creative Commons ${ }^{4}$ para produções multimídia. Isto representa para a indústria cultural um importante embate político e econômico, consideradas as ações deste tipo de comunidade que privilegia o uso justo e ético das tecnologias da informação e comunicação e, incentiva a sociedade civil a uma organização balizada por princípios como liberdade, segurança e privacidade na rede. E quais liberdades seriam estas? Nesse sentido, Silveira $(2004$, p. 9) é bastante didático e esclarece:

as quatro liberdades que caracterizam o software livre são as de uso, cópia, modificações e redistribuição. Richard Stallman, presidente da Free Software Foundation (Fundação do Software Livre), costuma comparar o software a uma receita de bolo. Ambos são um conjunto de instruções. Um software diz ao computador o que este deve fazer. Uma receita diz à pessoa as quantidades de cada ingrediente, a ordem em que devem ser misturados e outras orientações. Imagine se as pessoas fossem impedidas de trocar receitas? Ou se fossem proibidas de melhorar a receita que conseguiram de sua mãe ou de seu vizinho? Uma receita é um conjunto de ideias ou informações. Um software também.

\footnotetext{
3 General Public License (Licença Pública Geral) é a designação da licença para sofțware livre idealizada por Richard Stallman no fim da década de 1980, no âmbito do projecto GNU da Free Software Foundation (FSF) e é uma licença que utiliza os princípios do direito autoral para proteger o software livre e assegurar que ninguém possa torná-lo proprietário (SILVEIRA, 2004).

4 A iniciativa Creative Commons foi inventada nos Estados Unidos, em 2001, com um conjunto novo de licenças de conteúdo, cujo objetivo era o de flexibilizar o copyright, fornecendo, desta forma, uma ferramenta para fomentar a produção derivada e colaborativa de bens culturais. A iniciativa foi capitaneada no Brasil pela Escola de Direito da Fundação Getúlio Vargas (FGV) do Rio de Janeiro. A FGV trabalhou nas traduções e na adequação das licenças Creative Commons para legislação Brasileira (MURILLO, 2009).
} 
Segundo o autor, a ciência cresce a partir do princípio de compartilhamento e não a partir da ideia de propriedade e, por ser essencialmente social, não se aplica ao conhecimento a ideia de apropriação privada. O software livre possui um autor ou vários autores, mas não possui donos. E para isso, para ser efetivamente livre, deve-se necessariamente disponibilizar o seu código-fonte, o que contribui enormemente para a construção do modelo horizontal e colaborativo intitulado "bazar" (RAYMOND, 2001), na contramão da noção "catedral" que segue características hierárquicas e não colaborativas como no modelo proprietário.

Deste modo, o hackingé o símbolo maior da cibercultura, podendo ser visto pela ótica da astúcia dos usos (PERRIAULT, 1989), do desvio (BECKER, 1966) e da despesa improdutiva (BATAILLE, 1975), segundo Lemos (2004). Para este, a astúcia dos usos está relacionada à apropriação que tem uma dimensão técnica (o treinamento técnico, a destreza na utilização do objeto) e outra simbólica (uma descarga subjetiva, o imaginário) e significa, ao mesmo tempo, domínio, utilização e aprendizagem. O desvio se manifesta em relação às instruções de uso - um espaço completado pelo usuário na lacuna não programada pelo produtor/inventor ou mesmo pelas finalidades previstas inicialmente pelas instituições (LEMOS, 2004), ao mesmo tempo em que se constitui fora da lógica da produção e consumo das novas tecnologias.

O autor ainda reforça a análise de Becker em relação aos desviantes da cibercultura: aos hackers e outros outsiders da era da informação. A atitude hacker opera com o desejo de saber, desejo de ser livre e pela apropriação da técnica. Lemos (2004, p. 243) ainda sugere que "a noção de despesa como perda é ligada, aqui, à noção de sacrifício e destruição, fonte das coisas sagradas, dos jogos agonísticos e da arte em geral". Sugerindo exatamente o contrário do princípio da conservação.

Sobre a despesa improdutiva enquanto característica da cibercultura e especialmente da cultura hacker vale a pena citar:

G. Bataille vai mostrar que uma sociedade só existe se deixar um espaço reservado para despesas improdutivas, para perdas e excessos. Esta noção de excesso está na contramão do moralismo moderno, já que a acumulação capitalista e produtivista é a norma. Segundo Bataille, não há nada que nos permita definir o que é útil aos homens, já que os julgamentos, em geral, repousam sobre a produtividade social que, por sua vez, baseia-se no princípio em que todos os esforços e atividades devem ser redutíveis às necessidades materiais de produção e de conservação. Os prazeres furtivos, como a arte ou os jogos, são estas concessões, tendo um papel subsidiário na vida social (LEMOS, 2004, p. 242).

Está claro que os ativistas do Software Livre e membros destas comunidades virtuais estão engajados numa questão política que é cultural: uma revisão ética e estética das tecnologias de informação e comunicação. Para isso, multiplicam-se, frequentemente, ações ciberativistas em redes sociais online que sugerem uma politização do uso das tecnologias. Nesse sentido, Vegh (2003 apud RIGITANO, 2003) propõe três categorias de classificação do ativismo online.

A primeira categoria se refere à conscientização e apoio em que situa a internet como fonte alternativa de informação, de forma que indivíduos e organizações podem difundir informações e eventos não relatados ou relatados de forma parcial pela mídia de massa. A partir da obtenção de informações, por meio de visitas a sites, inscrição em listas de discussão ou participação de fóruns, pessoas de diferentes localidades podem entrar em contato com realidades até então desconhecidas, se sensibilizar, apoiar causas e até se mobilizar em prol de alguma organização, participando de ações e protestos online e off-line.

Outra categoria sugerida passa pelo ativismo de organização e mobilização e já insere o uso da rede para convidar pessoas para uma ação off-line, a partir do envio de emails e sites com data, local e horário de uma determinada mobilização. Um bom exemplo são os movimentos antiglobalização.

Já as iniciativas de ação/reação estão situadas nas ações online como ações diretas (pela internet) pró-ativas ou reativas, como invasão e/ou congestionamento de sites. Importante salientar aqui uma distinção entre a ação hacker e cracker. O primeiro se manifesta, comumente, pelo comportamento de apropriação social da técnica, o segundo, age rompendo, inclusive, com normas estabelecidas de segurança ou privacidade.

Também em evidência na rede, o Twitter tem se destacado como uma ferramenta web de 
microblogging, ${ }^{5}$ lançada em 2006, pela startup californiana Obvious Corp, ${ }^{6}$ que teve um crescimento exponencial cuja expressão $W$ hat's happening?, na sua página principal, tem motivado muitos usuários à adesão. No entanto, o que começou como uma trivialidade a partir da pergunta "o que você está fazendo?" levou a usos jamais imaginados (ALENCAR VIANA; MELO, 2009). Considerando este tipo de prática, alguns estudos indicam (ORIHUELA, 2007) quatro perfis dominantes no conteúdo das entradas do twitter, entre elas: as trivialidades cotidianas; as conversações em pequenas comunidades; compartilhamento de informações e url's; e a difusão de notícias e opiniões. E, entre os perfis dos usuários, o estudo destaca três categorias principais: os usuários que são fontes de informação; aqueles que se comunicam com amigos; e outros que usam a ferramenta para buscar informações.

Dessa maneira, a ferramenta se popularizou com diversos usos e se situou com grande potencial tanto para empresas como para organizações e ações ciberativistas. A internet é um espaço de comunicação no qual nada é excluído. Para Rigitano (2003), enquanto os anos 1980 foram caracterizados pelos movimentos sociais de base, a partir dos anos 1990, as ONGs e as redes de movimentos sociais (networks) passam a ocupar um papel central na análise das lutas sociais.

[...] enquanto as lutas sociais modernas eram marcadas por movimentos que mantinham a sua hierarquia condizente com os valores verticais da industrialização, as lutas contemporâneas apresentam movimentos sociais com uma estrutura cada vez mais horizontal e em rede (CASTELLS, 2001 apud RIGITANO, 2003, p. 2).

De acordo com Castells (1999 apud RIGITANO, 2003), as redes constituem a nova morfologia social de nossas sociedades e a difusão da lógica de redes modifica de forma substancial a operação e os resultados dos processos produtivos e de experiência, poder e cultura.
Dito isso, parece tornar-se evidente que as práticas sociopolíticas são culturais e requerem mudança de paradigmas para a vida cotidiana. Reconhecer a dimensão socioeducativa em potência da cibercultura significa ampliar espaços de intervenção para o animador cultural (GONZALES, 2007). $\mathrm{O}$ uso crescente das tecnologias digitais acompanha e amplifica uma profunda mutação na relação com o saber, sugerindo uma mudança de mentalidade, além da cultura dos sistemas educacionais tradicionais, sobretudo os papéis de professor e aluno. Não basta transpor cursos clássicos em formatos hipermídia interativos, é preciso instaurar uma aprendizagem cooperativa entre os sujeitos envolvidos (LEVY, 1999). O professor precisa de se imaginar não mais como difusor de conhecimentos, mas como um animador da inteligência coletiva; e parece interessante deslocar sua competência no sentido de incentivar a aprendizagem e o pensamento nesse contexto. Dessa maneira, estamos falando da transição de uma educação estritamente institucionalizada para uma situação de troca generalizada dos saberes, segundo Levy (1999), que nos é apresentada como um campo aberto e repleto de possibilidades para intervenções na educação não formal - o lazer.

\section{Considerações finais}

Apesar da mídia de massa, por vezes, explorar o lado conspiratório das tecnologias e fazê-lo de forma parcial, valorizando um isolamento social e negligenciando questões de controle social, há algo óbvio: não podemos escapar ao mundo tecnológico. Por isso, devemos tornar, quando oportuno, as tecnologias em ferramentas de prazer, de comunicação e de conhecimento, concordando com Lemos (2004). O desenvolvimento tecnológico, longe de ser apenas agente de separação, de alienação e de esgotamento de formas de solidariedade sociais, "pode servir como vetor de reliance, como instrumento de cooperação mútua e de solidariedades múltiplas" (LEMOS, 2004, p. 20):

\footnotetext{
${ }^{5}$ Microblogging é uma forma de publicação de blog que permite aos usuários que façam atualizações breves de texto (geralmente com menos de 200 caracteres) e publicá-las para que sejam vistas publicamente ou apenas por um grupo restrito escolhido pelo usuário. Estes textos podem ser enviados por uma diversidade de meios tais como SMS, mensageiro instantâneo, e-mail ou pela web.

THE OBVIOUS Corporation. Disponível em: <http://obvious.com/>. Acesso em: 20 fev. 2011.
} 
hoje, ao contrário do que acreditam pensadores de renome como Virilio e Baudrillard, não existe um sistema tecnológico que aniquile a vida social. É a rua que vai dar formas ao novo sistema técnico da cibercultura. Esta é a expressão do uso subversivo da tecnologia e, consequentemente, produto de uma atitude ativa em relação aos dispositivos técnicos (LEMOS, 2004, p. 245).

Também nessa direção, Levy (1999, p. 129) afirma que "é um erro pensar as relações entre antigos e novos dispositivos de comunicação em termos de substituição”. Para Levy (1999, p. 128) "é raro que a comunicação por meio de redes de computadores substitua pura e simplesmente os encontros físicos: na maior parte do tempo, é um complemento ou adicional".

Dessa forma, a atitude dispersa, efêmera e hedonista da socialidade contemporânea vai marcar, de forma constitutiva, a cibercultura:

as novas tecnologias da cibercultura devem nos ajudar a fazer diariamente de nossa vida uma obra de arte, aqui e agora; a tecnologia deve tornar-se um instrumento fundamental de compartilhamento de experiências, de prazer estético e de busca de informação multimodal e multidirecional (LEMOS, 2004, p. 245).

Assim, recorro a Shusterman (1998, p. 15), ao afirmar que "a estética torna-se muito mais central e significativa quando admitimos que, ao abranger o prático, ao refletir e informar sobre a práxis da vida, ela também diz respeito ao social e ao político". Assim como a tese de Lemos (2004) leva à constatação de que a cibercultura parte do encontro com a sociabilidade contemporânea com as tecnologias digitais, poderíamos supor que a estetização e a politização da técnica e tecnologia se constituem como um aspecto da vivência do lazer na rede por meio dos usos, apropriações, desvios e despesa improdutiva. Compreendendo aqui que a estetização e a politização não se excluem, mas se complementam, pois o uso desta tecnologia redefiniu a noção de comunidade e a reciprocidade tornou-se um princípio para muitos. O conhecimento sensível e a construção de si na relação com o outro tornam-se, portanto, imprescindíveis na produção de significado nestas práticas de lazer. Essa mobilização - compreendida como processo de convocação das vontades - que exige o acesso às questões técnicas e dos meios de comunicação, evoca uma reivindicação pelo direito à liberdade de expressão e, dessa forma, serve de veículo para transformação da realidade. Nesta esteira, a comunicação também assume um caráter pedagógico, pois contribui para ampliar o repertório e as atitudes por meio de interações com o mundo e, assim, o ser humano se modifica e se constrói (HENRIQUES, 2007).

Para finalizar, interessada em compreender uma possível práxis da cibercultura e explorar o lazerprodução de sentidos e significados no tempo livreaponto o ciberespaço como um novo espaço de intervenção para o profissional do lazer em um contexto social cada vez mais marcado pelo imperativo do acesso e conexão à internet. Se Dumazedier (1994), sugere o lazer como tempo social de revisão ética e estética, podemos pensar e operar com a politização e estetização da técnica como aspecto possível do lazer na rede? Nesse sentido, cabe a pergunta: o que a tecnologia fez com o lazer e o que o lazer pode fazer com a tecnologia? (ALENCAR VIANA, 2010). É uma questão que motiva longos debates e textos inacabáveis e, que particularmente, nos interessam.

\section{Referências}

AGUIAR, V. M. de. Os argonautas da internet: uma análise netnográfica sobre a comunidade online de software livre do Projeto Gnome à luz da Teoria da Dádiva. 2007. 100 f. Dissertação (Mestrado em Administração) Escola de Administração, Universidade Federal da Bahia, Salvador, 2007.

ALENCAR VIANA, J. de; MELO, V. A. de. Lazer e tecnologias da informação e comunicação (TICs): desafios para pensar a animação cultural na rede-um estudo da comunidade Estudiolivre.Org. 2010. 133 f. Dissertação (Mestrado em Lazer) - Universidade Federal de Minas Gerais, Escola de Educação Física, Fisioterapia e Terapia Ocupacional, Programa de Mestrado em Lazer, 2010.

BATAILLE, G. A parte maldita: precedida de a noção de despesa. Rio de Janeiro: Imago, 1975.

BECKER, H. S. Outsiders. Studies in the Sociology of Deviance. New York: The Free Press Becker, 1966. 
DUMAZEDIER, J. A revolução cultural do tempo livre. São Paulo: Studio Nobel; SESC São Paulo, 1994.

GODBOUT, J. T. Homo donator versus Homo oeconomicus. In: MARTINS, P. H. A dádiva entre os modernos. Petrópolis: Vozes, 2002. p. 63-97.

GONZALES, M. V. La animación cibercultural: la animación sociocultural en la Sociedad del Conocimiento. Zaragoza: Editorial Certeza, 2007.

HENRIQUES, M. S. (Org.). Comunicação e estratégias de mobilização social. Belo Horizonte: Autêntica, 2007.

KUMAR, K. Da sociedade pós-industrial a pós-moderna: novas teorias sobre o mundo contemporâneo. Rio de Janeiro: Jorge Zahar, 1997.

LEMOS, A. Cibercultura: tecnologia e vida social na cultura contemporânea. Porto Alegre: Sulina, 2004.

LEVY, P. Cibercultura. São Paulo: Editora 34, 1999.

MARZANO, A.; MELO, V. A. (Org.). Vida divertida: histórias do lazer no Rio de Janeiro (1830-1930). Rio de Janeiro: Apicuri, 2010.

MAUSS, M. Ensaio sobre a dádiva. Lisboa: Edições $70,1988$.

MELO, V. A. de. A animação cultural: conceitos e propostas. Campinas: Papirus, 2006.

MURILLO, L. F. R. Tecnologia, política e cultura na comunidade brasileira de Software Livre e de Código Aberto. 2009. 173 f. Dissertação (Mestrado em Antropologia Social) - Instituto de Filosofia e Ciências Humanas, Universidade Federal do Rio Grande do Sul, Porto Alegre, 2009.
ORIHUELA, J. L. Twitter y el boom del microblogging. Facultad de Comunicación. Pespectivas Del Mundo de La Comunicacion, n. 43, p. 2-3, 2007. Disponível em: <http://www.unav.es/comunicacion/perspectivas/ trayectoria.html>. Acesso em: 4 maio 2011.

PERRIAULT, J. La logique de L'usage: essais sur lês machines à communiquer. Paris: Flammarion, 1989.

RAYMOND, E. S. The catedral and the Bazaar: musing on Linux and Open Source by an accidental revolutionary. Sebastopol: O’Reilly Media, 2001.

RIGITANO, M. E. C. Redes e ciberativismo: notas para uma análise do Centro de Mídia Independente. In: SEMINÁRIO INTERNO DO GRUPO DE PESQUISA EM CIBERCIDADES, 1., 2003, Salvador. Anais... Salvador: FACOM/UFBA, 2003.

SHUSTERMAN, R. Vivendo a arte: o pensamento pragmatista e a estética popular. São Paulo: Editora 34, 1998.

SILVEIRA, S. A. da. Software livre: a luta pela liberdade do conhecimento. São Paulo: Perseu Abramo, 2004.

SODRÉ, M. As estratégias sensíveis: afeto, mídia e política. Petrópolis: Vozes, 2006.

THE OBVIOUS Corporation. Disponível em: < http:/ / obvious.com/>. Acesso em: 20 fev. 2011.

Recebido: $27 / 05 / 2011$

Received: 05/27/2011

Aprovado: $15 / 10 / 2011$ Approved:10/15/2011 